\title{
3 Research Square \\ Predictors for Development of Oxaliplatin-induced Peripheral Neuropathy in Cancer Patients as Determined by Ordered Logistic Regression Analysis
}

Yuko Kanbayashi ( $\nabla$ yuko.kambayashi@ompu.ac.jp )

Osaka Yakka Daigaku https://orcid.org/0000-0002-0095-2293

Takeshi Ishikawa

Kyoto Prefectural University of Medicine: Kyoto Furitsu Ika Daigaku

Yoshiaki Kuriu

Kyoto Prefectural University of Medicine: Kyoto Furitsu Ika Daigaku

Yusuke Tabuchi

Kyoto Prefectural University of Medicine: Kyoto Furitsu Ika Daigaku

Eigo Otsuji

Kyoto Prefectural University of Medicine: Kyoto Furitsu Ika Daigaku

Koichi Takayama

Kyoto Prefectural University of Medicine: Kyoto Furitsu Ika Daigaku

\section{Research Article}

Keywords: oxaliplatin, peripheral neuropathy, body mass index, number of cycles, SOX regimen, proton pump inhibitor

Posted Date: November 15th, 2021

DOl: https://doi.org/10.21203/rs.3.rs-847675/v2

License: (9) This work is licensed under a Creative Commons Attribution 4.0 International License. Read Full License 


\section{Abstract}

Purpose This retrospective study aimed to identify predictors for the development of oxaliplatin-induced peripheral neuropathy (OXAIPN).

Methods Between January 2017 and March 2021, a total 322 cancer patients at our hospital who were receiving oxaliplatin were enrolled. For the regression analysis of factors associated with oxaliplatininduced peripheral neuropathy, variables were extracted manually from medical charts. The level of OXAIPN was evaluated using the National Cancer Institute's Common Terminology Criteria for Adverse Events (version 5). Multivariate ordered logistic regression analysis was performed to identify predictors for the development of OXAIPN. Optimal cut-off thresholds were determined using receiver operating characteristic (ROC) analysis. Values of $P<0.05$ (2-tailed) were considered significant.

Results Significant factors identified included body mass index $(B M I)$ (odds ratio $[O R]=1.06,95 \%$ confidence interval $[\mathrm{Cl}]=1.00-1.12 ; P=0.046)$, number of cycles $(\mathrm{OR}=1.09,95 \% \mathrm{Cl}=1.05-1.14 ; P$ $<0.0001)$, S-1 plus oxaliplatin (SOX) regimen (OR $=0.54,95 \% \mathrm{Cl}=0.32-0.92 ; P=0.023)$, concomitant use of proton pump inhibitors (PPIs) $(\mathrm{OR}=1.64,95 \% \mathrm{Cl}=1.05-2.58 ; P=0.031)$ and concomitant use of analgesic adjuvant $(\mathrm{OR}=3.30,95 \% \mathrm{Cl}=1.09-9.97 ; P=0.035)$.

Conclusion BMI, number of cycles, SOX regimen, concomitant use of PPIs and concomitant use of analgesic drugs were identified as significant predictors for the development of OXAIPN.

\section{Introduction}

Oxaliplatin is a platinum-derivative chemotherapeutic agent used for chemotherapy in patients with colorectal, pancreatic, and gastric cancer [1-3]. Oxaliplatin causes acute cold-induced neurotoxicity and chronic cumulative neuropathy, which can require dose modification and impacts quality of life (QOL) [46]. Early identification of the neurotoxicity and changes in dosage or dosing schedule could prevent the development of chronic symptoms, which, once established, may take many months or years to resolve, or may even persist throughout life with substantial detrimental effects on QOL. However, to date, preventative and therapeutic strategies have not proven effective and identification of patients at risk is therefore important to maximize therapeutic efficacy while minimizing neurotoxicity. In addition, individual differences are seen in the severity of oxaliplatin-induced peripheral neuropathy (OXAIPN). This retrospective study was therefore undertaken to identify predictors associated with the development of OXAIPN to help guide future strategies toward improving safety, efficacy, and QOL among cancer patients treated with oxaliplatin.

\section{Patients And Methods}

\section{Study Period and Participants}


This study retrospectively analysed 322 cancer patients who received oxaliplatin at our hospital between January 2017 and March 2021. The Medical Ethics Review Committee of the Kyoto Prefectural University of Medicine approved this study (approval no. ERB-C-867-3). All procedures were performed in accordance with the ethical standards of the Kyoto Prefectural University of Medicine Institutional Medical Ethics Review Committee and the 1964 Declaration of Helsinki and its later amendments. No prospective studies with human participants or animals were performed by any of the authors for this article. Given the retrospective nature of this work, the need to obtain informed consent was waived for the individual participants included in the study, in accordance with the standards of the Kyoto Prefectural University of Medicine Institutional Medical Ethics Review Committee.

\section{Extraction of Variables}

For the regression analysis of factors associated with OXAIPN, variables were extracted manually from medical charts. Evaluated variables included factors that could potentially impact the development of OXAIPN: demographic data (sex, age, height, weight, body surface area and BMI), type of cancer, number of cycles, concomitant medications (PPIs, RAS inhibitors, analgesic adjuvant), chemotherapy regimen, presence of comorbidities (diabetes mellitus), and laboratory test values. Creatinine clearance was estimated using the Cockcroft and Gault equation based on serum creatinine, sex, age, and weight. Clinical information was extracted before administration of the first dose of oxaliplatin. Concomitant medication was defined as administration of another drug for $\geq 2$ weeks at the time of evaluation. The level of OXAIPN was evaluated using the National Cancer Institute Common Toxicity Criteria for Adverse Events (NCI-CTCAE; version 5). The degree of OXAIPN was evaluated at the time of final oxaliplatin administration.

\section{Statistical Analysis}

Independent variables were analysed for multicollinearity (correlation coefficient $|r| \geq 0.7$ ), since correlations among variables can lead to unreliable and unstable results of regression analyses. Independent variables were extracted based on the strength of the correlation with the level of OXAIPN (dependent variable) or clinical significance. First, univariate ordered logistic regression analyses between outcomes and each potential independent variable were performed. Subsequently, a multivariate ordered logistic regression model was constructed by employing the forward-backward stepwise selection procedure with the resulting candidate variables. The model used a variable entry criterion of 0.15 and a variable retention criterion of 0.1 . Ordered logistic regression analysis was employed, because the level of OXAIPN was evaluated by a graded scale and multiple factors really associated as predictors for the development of OXAIPN had to be analysed concurrently. Optimal cut-off thresholds were determined using ROC curve analysis.

For all statistical analyses, values of $P<0.05$ (two-tailed) were considered significant. All analyses were performed using JMP version 14.3.0 (SAS Institute, Cary, NC).

\section{Results}


All 322 patients who received oxaliplatin were enrolled in this study. Table 1 presents the clinical characteristics of the 322 enrolled patients, the potential variables related to the development of OXAIPN, and the results of univariate analyses. Stepwise selection identified the following candidate variables: male sex, body mass index (BMI), number of cycles, chemotherapy regimen as a combination of 5fluorouracil, oxaliplatin, irinotecan and leucovorin (FOLFIRINOX) or S-1 plus oxaliplatin (SOX), use of renin-angiotensin system (RAS) inhibitors, use of proton pump inhibitors (PPIs), and use of analgesic adjuvants (mirogabalin, pregabalin, or duloxetine). S-1 is an orally available chemotherapeutic agent comprising tegafur (a prodrug of fluorouracil [5-FU]), gimeracil (preventing dihydropyrimidine dehydrogenase-mediated degradation of 5-FU), and oteracil (reducing the toxic effects of 5-FU). Multivariate ordered logistic regression analysis was performed using these variables. Significant factors identified included $\mathrm{BMI}$ (odds ratio $[\mathrm{OR}]=1.06,95 \%$ confidence interval $[\mathrm{Cl}]=1.00-1.12 ; P=0.046$ ), number of cycles $(\mathrm{OR}=1.09,95 \% \mathrm{Cl}=1.05-1.14 ; P<0.0001)$, sOX regimen $(\mathrm{OR}=0.54,95 \% \mathrm{Cl}=0.32-$ $0.92 ; P=0.023)$, concomitant use of PPI $(\mathrm{OR}=1.64,95 \% \mathrm{Cl}=1.05-2.58 ; P=0.031)$ and concomitant use of analgesic adjuvant $(\mathrm{OR}=3.30,95 \% \mathrm{Cl}=1.09-9.97 ; P=0.035)$ (Table 2). Receiver operating characteristic (ROC) analysis revealed that OXAIPN (grade 2 or higher) was more likely to occur with BMI $\geq 20.5 \mathrm{~kg} / \mathrm{m}^{2}$, with $63.3 \%$ sensitivity and $47.8 \%$ specificity (area under the curve [AUC] $=0.54$ ), and number of cycles $\geq 8$ cycles, with $66.3 \%$ sensitivity and $56.5 \%$ specificity (AUC $=0.65$ ). 
Table 1

Patient characteristics, extracted variables, and results of univariate analyses ( $n=322$ )

$\begin{array}{llllll}\text { Grade } 0 & \text { Grade 1 } & \text { Grade 2 } & \text { Grade 3 } & \text { Pvalue } & \begin{array}{l}\text { Odds } \\ \text { ratio }\end{array} \\ (n=64) & (n= & (n=69) & (n=23) & & (95 \% \mathrm{Cl})\end{array}$

\section{Demographic data}

\begin{tabular}{|c|c|c|c|c|c|c|}
\hline Male, n (\%) & $\begin{array}{l}50 \\
(76.9)\end{array}$ & $\begin{array}{l}105 \\
(63.6)\end{array}$ & $\begin{array}{l}38 \\
(55.1)\end{array}$ & $\begin{array}{l}14 \\
(60.9)\end{array}$ & $0.015^{\star}$ & $\begin{array}{l}0.58 \\
(0.38- \\
0.90)\end{array}$ \\
\hline Age (y), median (range) & $\begin{array}{l}69 \\
(46-88)\end{array}$ & $\begin{array}{l}70 \\
(32-90)\end{array}$ & $\begin{array}{l}68 \\
(39-86)\end{array}$ & $\begin{array}{l}67 \\
(27-83)\end{array}$ & 0.279 & $\begin{array}{l}0.99 \\
(0.97- \\
1.01)\end{array}$ \\
\hline Height (cm), median (range) & $\begin{array}{l}164.8 \\
(147.5- \\
189.2)\end{array}$ & $\begin{array}{l}163.5 \\
(145- \\
184.8)\end{array}$ & $\begin{array}{l}165.1 \\
(142- \\
177.6)\end{array}$ & $\begin{array}{l}164.5 \\
(145- \\
176)\end{array}$ & 0.097 & $\begin{array}{l}0.98 \\
(0.96- \\
1.00)\end{array}$ \\
\hline Weight $(\mathrm{kg})$, median (range) & $\begin{array}{l}54.8 \\
(28.4-94)\end{array}$ & $\begin{array}{l}55.3 \\
(31.1- \\
89)\end{array}$ & $\begin{array}{l}55.6 \\
(31.2- \\
103)\end{array}$ & $\begin{array}{l}59 \\
(39.3- \\
80)\end{array}$ & 0.598 & $\begin{array}{l}1.00 \\
(0.99- \\
1.10)\end{array}$ \\
\hline BMI (kg/m²), median (range) & $\begin{array}{l}20.6 \\
(12.2- \\
31.2)\end{array}$ & $\begin{array}{l}20.8 \\
(12.7- \\
30.7)\end{array}$ & $\begin{array}{l}20.8 \\
(13.2- \\
33.7)\end{array}$ & $\begin{array}{l}21.9 \\
(16.1- \\
28.4)\end{array}$ & 0.117 & $\begin{array}{l}1.04 \\
(0.99- \\
1.10)\end{array}$ \\
\hline $\mathrm{BSA}\left(\mathrm{m}^{2}\right)$, median (range) & $\begin{array}{l}1.59 \\
(1.14- \\
2.08)\end{array}$ & $\begin{array}{l}1.59 \\
(1.16- \\
2.09)\end{array}$ & $\begin{array}{l}1.59 \\
(1.13- \\
2.20)\end{array}$ & $\begin{array}{l}1.63 \\
(1.33- \\
1.90)\end{array}$ & 0.877 & $\begin{array}{l}0.92 \\
(0.30- \\
2.79)\end{array}$ \\
\hline
\end{tabular}

\section{Cancer type}

Gastric, n (\%)

28

$(43.1)$
54

(32.7)
18

$(26.1)$
6

(26.1)
$0.032 * \quad 0.62$

$(0.40-$ $0.96)$

$\mathrm{Cl}$, confidence interval; BMI, body mass index; BSA, body surface area; FOLFOX, chemotherapy regimen consisting of fluorouracil plus oxaliplatin; SOX, chemotherapy regimen consisting of tegafur gimeracil oteracil potassium capsule (S-1) plus oxaliplatin; XELOX, chemotherapy regimen consisting of capecitabine plus oxaliplatin; FOLFIRINOX, chemotherapy regimen consisting of oxaliplatin, irinotecan, fluorouracil, and leucovorin; RAS, renin-angiotensin system; NSAIDs, non-steroidal antiinflammatory drugs.

$\star P<0.05$ 


\begin{tabular}{|c|c|c|c|c|c|c|}
\hline & $\begin{array}{l}\text { Grade } 0 \\
(n=64)\end{array}$ & $\begin{array}{l}\text { Grade } 1 \\
(n= \\
165)\end{array}$ & $\begin{array}{l}\text { Grade } 2 \\
(n=69)\end{array}$ & $\begin{array}{l}\text { Grade } 3 \\
(n=23)\end{array}$ & $P$ value & $\begin{array}{l}\text { Odds } \\
\text { ratio } \\
(95 \% \mathrm{Cl})\end{array}$ \\
\hline \multirow[t]{2}{*}{ Pancreas, n (\%) } & 5 & 18 & 5 & 2 & 0.899 & 0.96 \\
\hline & (7.7) & $(10.9)$ & $(7.2)$ & $(8.7)$ & & $\begin{array}{l}(0.47- \\
1.94)\end{array}$ \\
\hline \multirow[t]{2}{*}{ Colorectal, n (\%) } & 32 & 89 & 45 & 14 & $0.049 *$ & 1.52 \\
\hline & $(49.2)$ & $(53.9)$ & $(65.2)$ & $(60.9)$ & & $\begin{array}{l}(1.001- \\
2.31)\end{array}$ \\
\hline \multicolumn{7}{|l|}{ Comorbidity } \\
\hline \multirow[t]{2}{*}{ Diabetes mellitus, n (\%) } & 12 & 24 & 8 & 8 & 0.763 & 1.09 \\
\hline & $(18.5)$ & $(14.5)$ & $(11.6)$ & $(34.8)$ & & $\begin{array}{l}(0.62- \\
1.90)\end{array}$ \\
\hline \multicolumn{7}{|c|}{ Laboratory test value before administration } \\
\hline \multirow{2}{*}{$\begin{array}{l}\text { Serum creatinine, mg/dL, } \\
\text { median (range) }\end{array}$} & 0.77 & 0.73 & 0.64 & 0.71 & 0.446 & 0.69 \\
\hline & $\begin{array}{l}(0.35- \\
1.2)\end{array}$ & $\begin{array}{l}(0.36- \\
1.92)\end{array}$ & $\begin{array}{l}(0.41- \\
1.77)\end{array}$ & $\begin{array}{l}(0.36- \\
1.27)\end{array}$ & & $\begin{array}{l}(0.26- \\
1.80)\end{array}$ \\
\hline \multirow{2}{*}{$\begin{array}{l}\text { Creatinine clearance, } \mathrm{mL} / \mathrm{min} \text {, } \\
\text { median (range) }\end{array}$} & 74.9 & 70.1 & 71.4 & 82.6 & 0.178 & 1.01 \\
\hline & $\begin{array}{l}(28.2- \\
127.4)\end{array}$ & $\begin{array}{l}(34.1- \\
204.7)\end{array}$ & $\begin{array}{l}(25- \\
168.1)\end{array}$ & $\begin{array}{l}(37.4- \\
119.9)\end{array}$ & & $\begin{array}{l}(0.998- \\
1.013)\end{array}$ \\
\hline \multirow[t]{2}{*}{ Number of cycles } & 5 & 8 & 9 & 8 & $<.0001^{*}$ & 1.10 \\
\hline & $(1-32)$ & $(1-34)$ & $(2-31)$ & $(1-17)$ & & $\begin{array}{l}(1.05- \\
1.14)\end{array}$ \\
\hline \multicolumn{7}{|l|}{ Regimen } \\
\hline \multirow[t]{2}{*}{ FOLFOX } & 8 & 25 & 20 & 5 & $0.014^{\star}$ & 1.96 \\
\hline & (12.3) & (15.2) & $(29.0)$ & $(21.7)$ & & $\begin{array}{l}(1.15- \\
3.34)\end{array}$ \\
\hline
\end{tabular}

$\mathrm{Cl}$, confidence interval; BMI, body mass index; BSA, body surface area; FOLFOX, chemotherapy regimen consisting of fluorouracil plus oxaliplatin; SOX, chemotherapy regimen consisting of tegafur gimeracil oteracil potassium capsule (S-1) plus oxaliplatin; XELOX, chemotherapy regimen consisting of capecitabine plus oxaliplatin; FOLFIRINOX, chemotherapy regimen consisting of oxaliplatin, irinotecan, fluorouracil, and leucovorin; RAS, renin-angiotensin system; NSAIDs, non-steroidal antiinflammatory drugs. 


\begin{tabular}{|c|c|c|c|c|c|c|}
\hline & $\begin{array}{l}\text { Grade } 0 \\
(n=64)\end{array}$ & $\begin{array}{l}\text { Grade } 1 \\
(n= \\
165)\end{array}$ & $\begin{array}{l}\text { Grade } 2 \\
(n=69)\end{array}$ & $\begin{array}{l}\text { Grade } 3 \\
(n=23)\end{array}$ & $P$ value & $\begin{array}{l}\text { Odds } \\
\text { ratio } \\
(95 \% \mathrm{Cl})\end{array}$ \\
\hline \multirow[t]{2}{*}{ sox } & 27 & 45 & 11 & 5 & $0.001 *$ & 0.46 \\
\hline & $(41.5)$ & $(27.3)$ & $(15.9)$ & $(21.7)$ & & $\begin{array}{l}(0.28- \\
0.73)\end{array}$ \\
\hline \multirow[t]{2}{*}{ XELOX } & 22 & 70 & 30 & 7 & 0.624 & 1.11 \\
\hline & $(33.8)$ & $(42.4)$ & $(43.5)$ & $(30.4)$ & & $\begin{array}{l}(0.73- \\
1.69)\end{array}$ \\
\hline \multirow[t]{2}{*}{ FOLFIRINOX } & 4 & 18 & 6 & 2 & 0.729 & 1.13 \\
\hline & $(6.2)$ & $(10.9)$ & $(8.7)$ & $(8.7)$ & & $\begin{array}{l}(0.56- \\
2.30)\end{array}$ \\
\hline \multicolumn{7}{|c|}{ History of treatment with anticancer drugs } \\
\hline \multirow[t]{2}{*}{ Cisplatin } & 0 & 5 & 3 & 0 & 0.390 & 1.77 \\
\hline & & (3.0) & $(8.7)$ & & & $\begin{array}{l}(0.48- \\
6.52)\end{array}$ \\
\hline \multirow[t]{2}{*}{ Taxane } & 1 & 8 & 3 & 2 & 0.245 & 1.81 \\
\hline & $(1.5)$ & $(4.8)$ & $(4.3)$ & $(8.7)$ & & $\begin{array}{l}(0.67- \\
4.89)\end{array}$ \\
\hline \multirow[t]{2}{*}{ Oxaliplatin } & 0 & 2 & 3 & 0 & 0.206 & 2.86 \\
\hline & & $(1.2)$ & $(4.3)$ & & & $\begin{array}{l}(0.56- \\
14.52)\end{array}$ \\
\hline \multicolumn{7}{|l|}{ Concomitant medication } \\
\hline \multirow[t]{2}{*}{ RAS inhibitors } & 12 & 19 & 7 & 3 & 0.202 & 0.67 \\
\hline & (18.4) & (11.5) & $(10.1)$ & $(13.0)$ & & $\begin{array}{l}(0.36- \\
1.24)\end{array}$ \\
\hline \multirow[t]{2}{*}{ Proton pump inhibitor } & 28 & 82 & 32 & 13 & 0.473 & 1.16 \\
\hline & $(43.1)$ & $(49.7)$ & $(46.4)$ & $(56.5)$ & & $\begin{array}{l}(0.77- \\
1.75)\end{array}$ \\
\hline
\end{tabular}

$\mathrm{Cl}$, confidence interval; BMI, body mass index; BSA, body surface area; FOLFOX, chemotherapy regimen consisting of fluorouracil plus oxaliplatin; SOX, chemotherapy regimen consisting of tegafur gimeracil oteracil potassium capsule (S-1) plus oxaliplatin; XELOX, chemotherapy regimen consisting of capecitabine plus oxaliplatin; FOLFIRINOX, chemotherapy regimen consisting of oxaliplatin, irinotecan, fluorouracil, and leucovorin; RAS, renin-angiotensin system; NSAIDs, non-steroidal antiinflammatory drugs. 


\begin{tabular}{|c|c|c|c|c|c|c|}
\hline & $\begin{array}{l}\text { Grade } 0 \\
(n=64)\end{array}$ & $\begin{array}{l}\text { Grade } 1 \\
(n= \\
165)\end{array}$ & $\begin{array}{l}\text { Grade } 2 \\
(n=69)\end{array}$ & $\begin{array}{l}\text { Grade } 3 \\
(n=23)\end{array}$ & $P$ value & $\begin{array}{l}\text { Odds } \\
\text { ratio } \\
(95 \% \mathrm{Cl})\end{array}$ \\
\hline Analgesic adjuvant & $\begin{array}{l}2 \\
(3.1)\end{array}$ & $\begin{array}{l}3 \\
(1.8)\end{array}$ & $\begin{array}{l}3 \\
(4.3)\end{array}$ & $\begin{array}{l}4 \\
(17.4)\end{array}$ & $0.009 *$ & $\begin{array}{l}4.19 \\
(1.44- \\
12.19)\end{array}$ \\
\hline Duloxetine & $\begin{array}{l}1 \\
(1.5)\end{array}$ & $\begin{array}{l}2 \\
(1.2)\end{array}$ & $\begin{array}{l}1 \\
(1.4)\end{array}$ & $\begin{array}{l}4 \\
(17.4)\end{array}$ & $0.002^{*}$ & $\begin{array}{l}8.11 \\
(2.17- \\
30.27)\end{array}$ \\
\hline $\begin{array}{l}\text { Gabapentinoids } \\
\text { (Pregabalin or mirogabalin) }\end{array}$ & $\begin{array}{l}1 \\
(1.5)\end{array}$ & $\begin{array}{l}2 \\
(1.2)\end{array}$ & $\begin{array}{l}2 \\
(2.9)\end{array}$ & 0 & 0.798 & $\begin{array}{l}1.24 \\
(0.24- \\
6.50)\end{array}$ \\
\hline NSAIDs & $\begin{array}{l}4 \\
(6.2)\end{array}$ & $\begin{array}{l}17 \\
(10.3)\end{array}$ & $\begin{array}{l}8 \\
(11.6)\end{array}$ & $\begin{array}{l}1 \\
(4.3)\end{array}$ & 0.623 & $\begin{array}{l}1.19 \\
(0.59- \\
2.42)\end{array}$ \\
\hline Opioids & 8 & 15 & 14 & $\begin{array}{l}1 \\
(4.3)\end{array}$ & 0.455 & $\begin{array}{l}1.27 \\
(0.67- \\
2.40)\end{array}$ \\
\hline \multicolumn{7}{|c|}{$\begin{array}{l}\mathrm{Cl} \text {, confidence interval; BMI, body mass index; BSA, body surface area; FOLFOX, chemotherapy } \\
\text { regimen consisting of fluorouracil plus Oxaliplatin; SOX, chemotherapy regimen consisting of tegafur } \\
\text { gimeracil oteracil potassium capsule (S-1) plus oxaliplatin; XELOX, chemotherapy regimen consisting } \\
\text { of capecitabine plus oxaliplatin; FOLFIRINOX, chemotherapy regimen consisting of oxaliplatin, } \\
\text { irinotecan, fluorouracil, and leucovorin; RAS, renin-angiotensin system; NSAIDs, non-steroidal anti- } \\
\text { inflammatory drugs. }\end{array}$} \\
\hline$\star P<0.05$ & & & & & & \\
\hline
\end{tabular}


Table 2

Results of multivariate ordered logistic regression analysis for variables extracted by forward selection (n = 322)

\begin{tabular}{|c|c|c|c|c|}
\hline \multirow[t]{2}{*}{ Variable } & \multirow[t]{2}{*}{$P$ value } & \multirow[t]{2}{*}{ Odds ratio } & \multicolumn{2}{|l|}{$95 \% \mathrm{Cl}$} \\
\hline & & & Lower $95 \%$ & Upper $95 \%$ \\
\hline Male & 0.139 & 0.71 & 0.45 & 1.12 \\
\hline BMI & $0.046^{*}$ & 1.06 & 1.00 & 1.12 \\
\hline Number of cycles & $<.0001^{*}$ & 1.09 & 1.05 & 1.14 \\
\hline sox & $0.023^{*}$ & 0.54 & 0.32 & 0.92 \\
\hline FOLFIRINOX & 0.179 & 0.59 & 0.27 & 1.28 \\
\hline RAS inhibitors & 0.239 & 0.68 & 0.35 & 1.30 \\
\hline Proton pump inhibitors & $0.031^{*}$ & 1.64 & 1.05 & 2.58 \\
\hline Analgesic adjuvant & $0.035^{\star}$ & 3.30 & 1.09 & 9.97 \\
\hline \multicolumn{5}{|c|}{$\begin{array}{l}\mathrm{Cl} \text {, confidence interval; BMI, body mass index; SOX, chemotherapy regimen consisting of tegafur } \\
\text { gimeracil oteracil potassium capsule (S-1) plus oxaliplatin; FOLFIRINOX, chemotherapy regimen } \\
\text { consisting of oxaliplatin, irinotecan, fluorouracil, and leucovorin; RAS, renin-angiotensin system. }\end{array}$} \\
\hline$\star P<0.05$ & & & & \\
\hline
\end{tabular}

\section{Discussion}

The multivariate ordered logistic regression analysis performed in this study showed that significant predictors for the development of OXAIPN included use of BMI, number of cycles, SOX regimen, concomitant use of PPI and concomitant use of an analgesic adjuvant. Although RAS inhibitor was not extracted as a significant variable in multivariate analysis, the combined use of RAS inhibitors tended to reduce OXAIPN.

In this study, BMI was extracted as a significant predictor for the development of OXAIPN. Obesity has been reported as a risk factor for chemotherapy-induced peripheral neuropathy (CIPN) [7-10]. The results of this study were also consistent with findings from previous studies. When the body fat content is high, anticancer drugs reportedly accumulate in adipose tissue and excretion is thus delayed [11]. This may be one reason why OXAIPN is more likely to occur in obese patients. On the other hand, there are many reports contrary to our result of this study that the effect of anticancer drugs is diminished in obese patients [12]. Further verification is needed in this issue.

The ROC curve analysis revealed a BMI cut-off of $20.5 \mathrm{~kg} / \mathrm{m}^{2}$ for the group likely to develop OXAIPN (grade 2 or higher). World Health Organization have defined obesity or overweight patients as individuals with $\mathrm{BMI} \geq 25 \mathrm{~kg} / \mathrm{m}^{2}$ [13]. However, in this study, CIPN was more likely to occur with $\mathrm{BMI} \geq 20.5 \mathrm{~kg} / \mathrm{m}^{2}$. 
This may be due to the difference in physique between Japanese and Westerners. In particular, CIPN in the lower limbs may be partly due to the weight load caused by obesity. Clinicians should pay close attention to the onset of OXAIPN among patients with $\mathrm{BMI} \geq 20.5 \mathrm{~kg} / \mathrm{m}^{2}$, not necessarily the obese population.

The results also showed that OXAIPN was more likely to develop as the number of administration cycles increased. ROC analysis revealed that OXAIPN (grade 2 or higher) was more likely to occur with $\geq 8$ cycles. Regarding the number of doses, OXAIPN reportedly tends to become chronic depending on the total dose [5, 14-17]. Beijers et al. demonstrated that a higher cumulative dose is associated with the development of long-term OXAIPN [15]. Careful attention should be paid to the cumulative dose of oxaliplatin, particularly administration of $\geq 8$ cycles.

Among the chemotherapy regimens, SOX therapy has resulted in a lower risk of developing OXAIPN. SOX therapy is administered every 3 weeks, while FOLFOX and FOLFIRINOX are administered every 2 weeks. The concept of the stop-and-go strategy (strategy of intermittent oxaliplatin treatment) was proposed in the OPTIMOX trial to avoid aggravation of OXAIPN [18]. Our results suggested the severity of OXAIPN can be prevented by increasing the dosing interval. Our results are consistent with the results of OPTIMOX trial that OXAIPN can be avoided using the stop-and-go strategy.

Previous studies have reported PPI as a risk factor for peripheral neuropathy [19-21]. Makunts et al. found a significant increase in a wide variety of peripheral neurological and neuropathic adverse events due to PPI [19]. They reported that an increased gastric $\mathrm{pH}$ level correlated with decreased levels of vitamin B12. In turn, B12 deficiency has been associated with reversible peripheral neuropathy [21]. Clinicians should thus be careful in prescribing PPIs when performing chemotherapy with oxaliplatin.

Although analgesic adjuvants tend to be used in combination therapy, the result was that OXAIPN developed even with analgesic adjuvants.

The analgesic adjuvants used to relieve the symptoms of OXAIPN during chemotherapy did not show adequate therapeutic efficacy. This finding supports earlier observations that effective analgesic adjuvants are currently unavailable for CIPN $[16,22,23]$.

Although not significant, concomitant use of RAS inhibitors was suggested to prevent OXAIPN [24]. Previous research has reported RAS inhibitors could prevent OXAIPN. Further research is needed on this point.

Several limitations to the current study need to be considered. First, the retrospective nature of the study may have decreased the validity of the data obtained. Second, since this study was performed at a single institute, prospective multicentre studies are needed to confirm the results.

In conclusion, BMI, number of cycles, SOX regimen, concomitant use of PPI and concomitant use of analgesic adjuvant were identified as significant predictors for the development of OXAIPN. However, our 
findings need to be confirmed in further studies. Nevertheless, these results may assist in developing strategies to improve the safety, efficacy, and QOL among patients receiving oxaliplatin.

\section{Declarations}

Acknowledgements We wish to thank all the patients and medical staff at University Hospital, Kyoto Prefectural University of Medicine who were involved in this study.

Author contributions Y.Ka.: concept and design, data acquisition, data analysis, data interpretation, manuscript writing; T.I., Y.T. and Y.Ku.: concept and design, data acquisition, data interpretation; E.O. and K.T.: concept and design, data interpretation, supervision of the manuscript. All authors read and approved the final manuscript.

Funding No funding was received for conducting this study.

Data availability Data not available due to ethical restrictions.

Code availability Not applicable

Ethics approval The Medical Ethics Review Committee of the Kyoto Prefectural University of Medicine approved this study (approval no. ERB-C-867-3). All procedures were performed in accordance with the ethical standards of the Kyoto Prefectural University of Medicine Institutional Medical Ethics Review Committee and the 1964 Declaration of Helsinki and its later amendments.

Consent to participate No prospective studies with human participants or animals were performed by any of the authors for this article. Given the retrospective nature of this work, the need to obtain informed consent was waived for the individual participants included in the study, in accordance with the standards of the Kyoto Prefectural University of Medicine Institutional Medical Ethics Review Committee.

Consent for publication All authors give their consent for this manuscript to be published in Supportive Care in Cancer.

Conflicts of interest All authors declare no conflict of interests concerning this work.

Informed consent No prospective studies with human participants or animals were performed by any of the authors for this article. Given the retrospective nature of this work, the need to obtain informed consent was waived for the individual participants included in the study, in accordance with the standards of the Kyoto Prefectural University of Medicine Institutional Medical Ethics Review Committee.

\section{References}

1. Qin S, Li J, Wang L, Xu J, Cheng Y, Bai Y, Li W, Xu N, Lin LZ, Wu Q, Li Y, Yang J, Pan H, Ouyang X, Qiu W, Wu K, Xiong J, Dai G, Liang H, Hu C, Zhang J, Tao M, Yao Q, Wang J, Chen J, Eggleton SP, Liu T 
(2018) Efficacy and Tolerability of First-Line Cetuximab Plus Leucovorin, Fluorouracil, and Oxaliplatin (FOLFOX-4) Versus FOLFOX-4 in Patients With RAS Wild-Type Metastatic Colorectal Cancer: The Open-Label, Randomized, Phase III TAILOR Trial. J Clin Oncol. 36: 3031-3039.

2. Boku N, Ryu MH, Kato K, Chung HC, Minashi K, Lee KW, Cho H, Kang WK, Komatsu Y, Tsuda M, Yamaguchi K, Hara H, Fumita S, Azuma M, Chen LT, Kang YK (2019) Safety and efficacy of nivolumab in combination with S-1/capecitabine plus oxaliplatin in patients with previously untreated, unresectable, advanced, or recurrent gastric/gastroesophageal junction cancer: interim results of a randomized, phase II trial (ATTRACTION-4). Ann Oncol. 30: 250-258

3. Conroy T, Hammel P, Hebbar M, Ben Abdelghani M, Wei AC, Raoul JL, Choné L, Francois E, Artru P, Biagi JJ, Lecomte T, Assenat E, Faroux R, Ychou M, Volet J, Sauvanet A, Breysacher G, Di Fiore F, Cripps C, Kavan P, Texereau P, Bouhier-Leporrier K, Khemissa-Akouz F, Legoux JL, Juzyna B, Gourgou S, O'Callaghan CJ, Jouffroy-Zeller C, Rat P, Malka D, Castan F, Bachet JB; Canadian Cancer Trials Group and the Unicancer-GI-PRODIGE Group (2018) FOLFIRINOX or Gemcitabine as Adjuvant Therapy for Pancreatic Cancer. N Engl J Med. 379: 2395-2406

4. Cavaletti G, Marmiroli P (2020) Management of Oxaliplatin-Induced Peripheral Sensory Neuropathy. Cancers (Basel). 12, 1370

5. Wei G, Gu Z, Gu J, Yu J, Huang X, Qin F, Li L, Ding R, Huo J. (2021) Platinum accumulation in oxaliplatin-induced peripheral neuropathy. J Peripher Nerv Syst. 26:35-42.

6. Kang L, Tian Y, Xu S, Chen H (2021) Oxaliplatin-induced peripheral neuropathy: clinical features, mechanisms, prevention and treatment. J Neurol. 268:3269-3282.

7. Mizrahi D, Park SB, Li T, Timmins HC, Trinh T, Au K, Battaglini E, Wyld D, Henderson RD, Grimison P, Ke H, Geelan-Small P, Marker J, Wall B, Goldstein D (2021) Hemoglobin, Body Mass Index, and Age as Risk Factors for Paclitaxel- and Oxaliplatin-Induced Peripheral Neuropathy. JAMA Netw Open. 4,e2036695

8. Cox-Martin E, Trahan LH, Cox MG, Dougherty PM, Lai EA, Novy DM (2017) Disease burden and pain in obese cancer patients with chemotherapy-induced peripheral neuropathy. Support Care Cancer. 25: 1873-1879

9. Petrovchich I, Kober KM, Wagner L, Paul SM, Abrams G, Chesney MA, Topp K, Smoot B, Schumacher M, Conley YP, Hammer M, Levine JD, Miaskowski C (2019) Deleterious Effects of Higher Body Mass Index on Subjective and Objective Measures of Chemotherapy-Induced Peripheral Neuropathy in Cancer Survivors. J Pain Symptom Manage. 58: 252-263

10. Sajdyk TJ, Boyle FA, Foran KS, Tong Y, Pandya P, Smith EML, Ho RH, Wells E, Renbarger JL (2020) Obesity as a Potential Risk Factor for Vincristine-induced Peripheral Neuropathy. J Pediatr Hematol Oncol. 42: e637-e640

11. Blouin RA, Warren GW (1999) Pharmacokinetic considerations in obesity. J Pharm Sci. 88:1-7.

12. Karatas F, Erdem GU, Sahin S, Aytekin A, Yuce D, Sever AR, Babacan T, Ates O, Ozisik Y, Altundag K (2017) Obesity is an independent prognostic factor of decreased pathological complete response to neoadjuvant chemotherapy in breast cancer patients. Breast. 32: 237-244 
13. World Health Organization. Body Mass Index-BMI. 2021. (https://www.euro.who.int/en/healthtopics/disease-prevention/nutrition/a-healthy-lifestyle/body-mass-index-bmi). Accessed October 4, (2021).

14. Yokoyama S, Nakagawa C, Hosomi K (2021) Treatment strategy of oxaliplatin-induced peripheral neuropathy: a retrospective, nationwide study. Support Care Cancer: in press

15. Beijers AJ, Mols F, Tjan-Heijnen VC, Faber CG, van de Poll-Franse LV, Vreugdenhil G (2015) Peripheral neuropathy in colorectal cancer survivors: the influence of oxaliplatin administration. Results from the population-based PROFILES registry. Acta Oncol. 54: 463-9

16. Kanbayashi Y, Hosokawa T, Okamoto K, Konishi H, Otsuji E, Yoshikawa T, Takagi T, Taniwaki M (2010) Statistical identification of predictors for peripheral neuropathy associated with administration of bortezomib, taxanes, oxaliplatin or vincristine using ordered logistic regression analysis. Anticancer Drugs. 21: 877-81

17. Hsu SY, Huang WS, Lee SH, Chu TP, Lin YC, Lu CH, Beaton RD, Jane SW (2019) Incidence, severity, longitudinal trends and predictors of acute and chronic oxaliplatin-induced peripheral neuropathy in Taiwanese patients with colorectal cancer. Eur J Cancer Care (Engl). 28: e12976

18. Tournigand C, Cervantes A, Figer A, Lledo G, Flesch M, Buyse M, Mineur L, Carola E, Etienne PL, Rivera F, Chirivella I, Perez-Staub N, Louvet C, André T, Tabah-Fisch I, de Gramont A (2006) OPTIMOX1: a randomized study of FOLFOX4 or FOLFOX7 with oxaliplatin in a stop-and-go fashion in advanced colorectal cancer: GERCOR study. J Clin Oncol. 24: 394-400

19. Makunts T, Alpatty S, Lee KC, Atayee RS, Abagyan R (2019) Proton-pump inhibitor use is associated with a broad spectrum of neurological adverse events including impaired hearing, vision, and memory. Sci Rep. 9: 17280

20. Rajabally YA, Jacob S (2005) Neuropathy associated with lansoprazole treatment. Muscle Nerve. 31: 124-5

21. Heidelbaugh JJ (2013) Proton pump inhibitors and risk of vitamin and mineral deficiency: evidence and clinical implications. Ther Adv Drug Saf. 4: 125-33

22. Loprinzi CL, Lacchetti C, Bleeker J, Cavaletti G, Chauhan C, Hertz DL, Kelley MR, Lavino A, Lustberg MB, Paice JA, Schneider BP, Lavoie Smith EM, Smith ML, Smith TJ, Wagner-Johnston N, Hershman DL (2020) Prevention and Management of Chemotherapy-Induced Peripheral Neuropathy in Survivors of Adult Cancers: ASCO Guideline Update. J Clin Oncol. 38: 3325-3348

23. Jordan B, Margulies A, Cardoso F, Cavaletti G, Haugnes HS, Jahn P, Le Rhun E, Preusser M, Scotté F, Taphoorn MJB, Jordan K; ESMO Guidelines Committee. Electronic address:

clinicalguidelines@esmo.org; EONS Education Working Group. Electronic address: eons.secretariat@cancernurse.eu; EANO Guideline Committee. Electronic address: office@eano.eu (2020) Systemic anticancer therapy-induced peripheral and central neurotoxicity: ESMO-EONS-EANO Clinical Practice Guidelines for diagnosis, prevention, treatment and follow-up. Ann Oncol. 31: 13061319 
24. Uchida M, Kawazoe H, Takatori S, Namba H, Uozumi R, Tanaka A, Kawasaki H, Araki H (2018) Preventive Effects of Renin-angiotensin System Inhibitors on Oxaliplatin-induced Peripheral Neuropathy: A Retrospective Observational Study. Clin Ther. 40: 1214-1222.e1 